\title{
Nationwide French study of RET variants detected from 2003 to 2013 suggests a possible influence of polymorphisms as modifiers
}

Maylis Lebeault ${ }^{1}$, Stéphane Pinson ${ }^{2,17}$, Marine Guillaud-Bataille ${ }^{3,17}$, Anne-Paule GimenezRoqueplo $^{4,17}$, Alain Carrie ${ }^{5,17}$, Véronique Barbu ${ }^{6,17}$, Pascal Pigny ${ }^{7,17}$, Stéphane Bezieau ${ }^{8,17}$, Jean-Marc Rey ${ }^{9,17}$, Chantal Delvincourt ${ }^{10,17}$, Sophie Giraud ${ }^{2,17}$, Charlotte Veyrat-

Durebex ${ }^{11,12,17}$, Patrick Saulnier ${ }^{15}$, Nathalie Bouzamondo ${ }^{12,17}$, Marie Chabert ${ }^{11}$, Julien Blin

${ }^{13}$,Amira Mohamed ${ }^{15,17}$, Pauline Romanet ${ }^{15,17}$, Francoise Borson-Chazot ${ }^{14,17}$, Vincent Rohmer ${ }^{1}$, Anne Barlier ${ }^{15,17}$, Delphine Mirebeau-Prunier ${ }^{11,12,17}$

1 Service d'Endocrinologie, CHU Angers, France

2 Laboratoire de Génétique Moléculaire, CHU Lyon, France

3 Laboratoire de Génétique, IGR Villejuif, France

4 Service de Génétique, AP-HP HEGP Paris, France

5 Centre de Génétique Moléculaire Chromosomique, AP-HP Paris, France

6 Laboratoire Commun de Biologie et Génétique Moléculaires, HUEP, SAT, AP-HP Paris, France

7 Laboratoire de Biochimie et Oncologie Moléculaire, CHU Lille, France

8 Laboratoire de Génétique Moléculaire, CHU Nantes, France

9 Laboratoire de Biopathologie Cellulaire et Tissulaire des Tumeurs, CHU Montpellier, France

10 Laboratoire de Biologie Oncologique, CHU Reims, France

11 Université d'Angers, UMR CNRS 6214, INSERM U1083, PREMMI, MITOVASC, Angers, France

12 Laboratoire de Biochimie et Biologie Moléculaire, CHU Angers, France

13 Institut National du Cancer - INCa, Paris, France 
14 Service d'Endocrinologie, Hospice Civile de Lyon, INSERM U 1052 et Université de Lyon 1, France

15 Aix Marseille Univ, CNRS, CRN2M, UMR 7286, and APHM La Conception Hospital, Molecular Biology Laboratory, Marseille, France

16 Cellule de Méthodologie et Biostatistiques, Délégation à la Recherche Clinique et I'Innovation-DRCl, CHU Angers, France

17 Réseau TenGen, France

Short title: RET variants in France

Key words: RET oncogene, Multiple Endocrine Neoplasia type 2 (MEN2), genetic variants, medullary thyroid cancer (MTC), pheochromocytoma (PHEO) 


\section{ABSTRACT}

Background: The presence of single nucleotide polymorphisms (SNPs) in the RET (REarranged during Transfection) gene has been investigated with regard to their potential role in the development or progression of medullary thyroid cancer (MTC) or pheochromocytomas (PHEO) in patients with the multiple endocrine neoplasia type 2 (MEN2) syndrome. The aim of this study was to evaluate the spectrum of RET variants in France between 2003 and 2013, and an evaluation of the impact of SNPs on the MEN2 A phenotype.

Methods: In this retrospective cohort study RET variants were screened in 5109 index cases and RET pathogenic variants were screened in 2214 relatives. Exons 5, 8, 10, 11, 13, 14, 15 and 16 were characterized by Sanger sequencing. RET Non-SNP pathogenic variants, $R E T$ variants with unknown functional significance (VUS), and four RET SNP variants, i.e. G691S (rs1799939), L769L (rs1800861), S836S (rs1800862), and S904S (rs1800863) were characterized and are reported in index cases. In silico analysis and classification following the recommendation of the ACMG (American College of Medical Genetics and Genomics) was performed for RET variants with unknown functional effects. Each patient's age at the time of diagnosis, sex, and the endocrine neoplasias present at molecular diagnosis were recorded.

Results: Twenty-six single non-SNP RET variants VUS in RET without any well-defined risk profiles were found in 33 patients. Nine of these were considered probably pathogenic, 11 of uncertain significance, and 6 as probably benign. Three double pathogenic variants found in 3 patients were classified as pathogenic. A study of the entire cohort showed that patients carrying non-SNP pathogenic variants or VUS in RET together with PHEO were diagnosed earlier than the others. The presence of the G691S SNP, or a combination of SNPs, increased the risk of developing PHEO, but did not modify the date of the diagnosis. No association was found between SNPs and medullary thyroid cancer (MTC) or hyperparathyroidism (HPTH). 
Conclusions: Our finding propose a classification of 15 of the 26 non-SNP RET variants VUS in RET without any well-defined risk profiles and suggest that the G691S SNP, or a combination of SNPs, may be associated with the development of PHEO. 


\section{INTRODUCTION}

The human gene RET (REarranged during Transfection) gene encodes the tyrosine kinase transmembrane receptor required for the normal development of cell types derived from the neural crest, e.g. the thyroid C cells or the adrenal chromaffin cells. Gain-offunction variants lead to the activation of the RET receptor and to an abnormal proliferation of these cells, which are pathognomonic in patients with multiple endocrine neoplasia type 2 (MEN2). The MEN2 syndrome includes two clinically distinct forms, MEN2A and MEN2B, associated with distinct mutations in the RET gene as summarized in the Revised American Thyroid Association (ATA) Guidelines for the Management of Medullary Thyroid Cancer (1). MEN2A includes medullary thyroid cancer (MTC) in combination or not with pheochromocytoma (PHEO) and hyperparathyroidism (HPTH). MEN2B is characterized by MTC, PHEO, ganglioneuromatosis, mucosal neuromas and a marfanoid habitus.

Germline gain-of-function RET variants mostly occur in exons 5, 8, 10, 11, 13, 14, 15 and 16. Various consortia as well as the ATA have defined the risk profiles of each variant for the risk and aggressivity of MTC, giving estimations of the penetrance of MEN, recommending the optimal age for prophylactic thyroidectomy, and suggesting that asymptomatic patients carrying a germline disease-causing RET variant should be screened for PHEO and $\operatorname{HPTH}(1,2)$. Some RET variants have not been categorized because of insufficient data. More information about these cases will be needed to provide adequate genetic counseling to patients and families. In 2010, an extensive study of RET variants in exon 10 evaluated the risk profiles of these patients and estimated the penetrance of MEN2 (3). The results showed that $50 \%$ penetrance was achieved by age 36 for MTC and by age 68 for PHEO. Another study analyzed clinical risk profiles and outcomes for RET variants at codon 634. The outcomes varied according to the amino acid substitution and C634R seemed to be associated with a more aggressive MEN2A phenotype (4). However, some of the conclusions concerning $R E T$ variants are controversial. A recent study focusing on the RET Y791F variant, classified as moderate risk by the ATA, reported no association between this variant and susceptibility to MTC (5). The authors found a frequency of 0.008 in the tumor-free cohorts originating in Central Europe. They, and other authors, also 
reported subjects harboring $R E T$ Y791F without the $\operatorname{MEN} 2$ syndrome $(5,6)$. It is therefore important to collect more data about patients in order to update the classification of $R E T$ variants in MTC.

The presence of single nucleotide polymorphisms (SNPs) in the RET gene has been investigated with regard to their potential role in the development or progression of MTC or PHEO in patients with the MEN2 syndrome. Four SNPs, i.e. G691S (rs1799939), L769L (rs1800861), S836S (rs1800862), and S904S (rs1800863), have been regularly studied in the context of MEN2. For each SNP, the findings were contradictory. Some clinical studies found an increased prevalence of RET SNPs in MTC (7-11), whereas others did not (12-14). A meta-analytic study on G691S, combining results from 968 cases of MTC and 2115 controls, found that female patients were at a higher risk of the disease than males (15). Other studies suggest a potential additive effect of these SNPs on the susceptibility to MTC or PHEO $(8,11)$. Taken together, these findings suggest that the consideration of the possible modifying role of these SNPs may contribute to better clinical and follow-up management.

Here we describe the spectrum of RET variants observed in the French population over the last 10 years collected from a nationwide database. We propose a classification of 32 genotypes that have not been classified by the ATA (16). Finally, we explore the effects of multiple RET SNPS on the MEN2A phenotype. 


\section{Patients and methods}

\section{Organization of RET gene analysis in France}

In France, genetic counseling and RET molecular analysis are recommended in the presence of MTC, isolated or in combination with PHEO and HPTH. It is provided free of charge to patients and their next of kin by the French National Cancer Institute (INCa). This institute, created under the French Public Health Act of 2004, plays a pivotal role in the national coordination of actions aimed at fighting cancer. Through its coordinated programs, INCa has funded a total of 11 laboratories across the country to perform RET molecular analyses, constituting the nationwide TenGen network.

\section{Database}

TenGen, which is affiliated with the French Endocrine Society, has set up an exhaustive national database to collect clinical and genetic information about these patients. The database has been declared to the French National Commission for Computerized Data and Individual Freedom (CNIL) and is registered under $\mathrm{N}^{\circ} 91513$. The TenGen network has verified all the data included in the RET database from 2003 to 2013. This study is nationwide and all centers performing RET gene analysis have contributed to the RET database.

\section{Patients}

Over the ten-year period from 2003 to 2013, 5109 index cases and 2214 relatives underwent RET proto-oncogene analysis. Index cases were diagnosed with various combinations of endocrine neoplasias, i.e. MTC, associated or not with PHEO or HPTH. Each index case belonged to apparently unrelated families according to the genetic counseling and the family name. Each laboratory was invited to anonymize and complete a form for each index case. The information collected included each patient's age at the time of diagnosis, sex, the endocrine neoplasias present, and the RET genetic variants. For screened relatives only the presence or absence of the RET pathogenic variant was available. 


\section{Molecular characterization}

The germline RET variants, including SNP, in exons 5, 8, 10, 11, 13, 14 and 16 were analyzed (Genbank reference NM_020975.4). Genomic DNA was obtained from peripheral blood leucocytes and the genotyping was done using direct sequencing.

We use "variant" as a neutral term, "pathogenic variant" for variants affecting RET function, and the term "polymorphism" or "SNP" for a variant found at a frequency above $1 \%$ or higher in the general population. The RET SNPs studied included G691S (rs1799939), L769L (rs1800861), S836S (rs1800862), and S904S (rs1800863). For variants for which a functional effect was not well-defined and that were not listed in the ATA MTC guidelines $(1,2,17)$, we used the term "variant of unknown significance" (VUS). The variants were also classified following the recommendation of the ACMG (16). In silico analysis was performed by three different in silico bioinformatics algorithms, i.e. the scale-invariant feature transform (SIFT), polymorphism phenotyping (PolyPhen-2) and the MutationTaster. The term "non-SNP RET variants" wasere used to group together "pathogenic variants" and "variants of unknown significance".

\section{Ethics}

Informed consent for genetic analysis and the use of data was obtained from all patients or their legal guardians according to the French governmental regulations.

\section{Statistical analysis}

Ordinal or nominal variables were summarized in terms of the frequency of occurrence and percentage, or the mean $( \pm s d)$ for continuous variables. Baseline characteristics were compared using either the Chi Square test for qualitative variables or Student's t-test for quantitative variables. Kaplan-Meier curves were used for estimating the age-related penetrance of MEN2A according to the presence of PHEO, and comparisons between curves were made with a log-rank test. Statistical analyses were performed using SPSS version 15 (SPSS Inc., Chicago, IL, USA). 


\section{RESULTS}

\section{Non-SNP Pathogenic variants and VUS in RET in France}

Over the 10-year period from 2003-2013, 7323 tests were carried out, of which 5109 concerned index cases and 2214 were used for family studies (Table 1). The frequency of non-SNP pathogenic variants and VUS in RET was $10.1 \%$ in the index cases, i.e. 514 of the 5109 patients tested, and $39.1 \%$ in the next of kin, i.e. 867 carriers of RET pathogenic variants found in 2214 patients studied. We collected genetic data in 480 of the 514 index cases (94.2\%) in which the 8 RET exons had been analyzed during the period 2003-2013. The mean age of the patients was $47.3 \pm 17.7$ years and $59.9 \%$ of the patients were women. The clinical feature at the time of diagnosis was MEN2A in 448 patients (93.3\%), and MEN2B in 32 patients (6.7\%).

Among the 480 index cases, 477 patients had missense single variants (Figure 1). Of the single variants found, $51.6 \%$ are located in the extra-cellular domain of the receptor, affecting the cysteine codons. The most frequent variants were V804M (17.2\%), C634R (11.0\%), C634Y (9.5\%), L790F (8.9\%) and M918T (6.0\%), whereas the other represented less than $5 \%$ (as shown in Supplemental Data 1).

Three of the patients had three different double variants, i.e (V804M; R844L); (K603Q; L790F); (D631Y; Y791F). Each of the variants observed was classified as pathogenic by the ATA; however, the double variants were not classified.

\section{Clinical and oncological features of patients carrying ATA classified variants}

Following the 2015 ATA Clinical Guidelines for MTC (1), the variants of 444 patients (92.3\%) were listed in the guidelines and these patients had a well defined risk profile. Among these, 268 patients in our study (55.7\%), could be qualified as carrying a "moderate risk" (corresponding to a combination of the former class A and class B pathogenic variants included in the 2009 ATA clinical guidelines (2), 146 patients (30.4\%) as being at "high risk" (former Class C pathogenic variants, that includes patients with the RET codon C634 and A883F pathogenic variants), and 30 patients (6.2\%) at the "highest risk" (former Class D pathogenic variants that includes MEN2B and RET codon M918T) (Figure 1). 


\section{Clinical and oncological features of patients carrying non ATA-classified variants}

Among the index cases, 36 patients (7.7\%) had variants not classified by the ATA, including 28 patients with 21 different single missense variants, 5 patients with 5 different synonymous RET variants, and three patients with double missense variants. Thirty patients were diagnosed with MTC and/or PHEO after age 40, whereas 6 patients were diagnosed before age 40 (Table 2).

Two of the 5 synonymous RET variants, i.e. C620C (c.1860C $>$ T) and S699S (c.2097C>T) have never been reported either in the NCBI dbSNP or in the Exome Aggregation Consortium (ExAC) databank: All patients with these variants were diagnosed after age 40 .

Of the 21 RET single variants not listed in the ATA classification (Table 2), 5 have never been reported either in the NCBI dbSNP or in the ExAC databank. Three of the latter, i.e. C515F (c.1544G>T), C541R (c.1621T>C) and N783S (c.2348A>G), were qualified as "damaging" by three different in silico bioinformatics algorithms. The patient who carried the C541R mutation was diagnosed before the age of one year with a suspicion of MEN2B and Hirschsprung's disease. The parents were asymptomatic, and no genetic analysis was performed for them. Unfortunately, we did not have access to additional clinical data on the patient to confirm MEN2B or Hirschprung's disease. The two other variants, V704F (c.2110G>T) and F644V (c.1930T>G), were qualified as "benign" or "damaging" depending on the bioinformatics tool used. The patient carrying the F644V substitution was diagnosed with MTC at age 35, and the patient carrying the V704F variant was diagnosed with HPTH at age 49.

Of the 16 single variants not classified by the ATA listed in the NCBI dbSNP or the ExAC databank, according to the 3 algorithms used, four were qualified as "benign" (one of the patients was diagnosed at age 21), five were qualified as "damaging" or "possibly damaging", and seven RET variants were qualified as being either "benign" or "damaging" according to the algorithm used (two of these patients were diagnosed before age 40) (Table 2). 
We used the criteria for classifying these 21 single $R E T$ variants with the consensus recommendation of the ACMG. Nine variants for 11 patients could be classified as probably pathogenic, six as probably benign, and the others as variants "of unknown significance" (VUS).

Clinical and oncological features of patients carrying RET double pathogenic variants

Each single variant found in these cases is already listed in the ATA MTC guidelines with a moderate risk of aggressive MTC but the risks for double mutations have not been reported. One patient with a concomitant V804M and R844L substitution was diagnosed with MTC at age 51, with a metastatic node. Her twin sister was diagnosed with MTC at the same age but without any metastatic nodes. The two pathogenic variants were on the same allele. The patient with K603Q and L790F had MTC alone at age 60. No family study was available for this patient. A 31-year-old male patient, diagnosed with PHEO, harbored D631Y and Y791F. The two variants were in distinct alleles. His father, carrying D631Y, was diagnosed with metastatic bilateral PHEO at age 65. No information was available for his mother.

The non-SNP variant spectrum of the RET codon in MEN2A is associated with PHEO and $\underline{\mathrm{HPTH}}$

We collected complete clinical information at the time of molecular analysis for 366 of the 448 MEN2A patients. Among these patients, $77.3 \%$ had MTC alone, $17.5 \%$ had MTC and PHEO, 3.3\% had MTC and HPTH, and $1.9 \%$ had MTC, PHEO and HPTH.

The frequency of patients for whom PHEO was the first appearing lesion was $19.4 \%$ (71 of the 366 MEN2A patients). All the variants were pathogenic and already listed in the ATA MTC guidelines, except for G548S and K666T. Sixty-one of the 71 patients with PHEO had predominantly variants in exons 10 or 11 and these mainly concerned cysteine residues for these exons, except for the K666T variant. The mean age at the time of molecular diagnosis of MEN2A was significantly different between patients with or without 
PHEO, respectively $41.8 \pm 13.0$ and $48.7 \pm 16.3$ years $(p=0.001$, Student's t-test and $\mathrm{p}<0.0001$, Log-rank test) (Figure 2).

Codon 634, which was most frequently mutated, was found to be affected in 112 patients among which $55(49,1 \%)$ had PHEO. In this group of 112 patients, 43 had C634R (38,4\%), 33 had C634Y (29,5\%), 11 had C634W (9,8\%), 11 had C634S (9,8\%), 6 had C634G $(5,4 \%), 6$ had C634F $(5,4 \%)$, and 2 had C634L (1,8\%). The risk of PHEO was about $50 \%$ for each variant except for $\mathrm{C} 634 \mathrm{~F}$, where it was lower at $17 \%$. The mean age at the time of diagnosis did not significantly differ between patients, with or without PHEO, harboring a codon 634 pathogenic variant.

HPTH was found in 19 of the 366 MEN2A patients (5.2\%). All the mutations were pathogenic variants already listed in the ATA MTC guidelines except for V704F. Thirteen of these 19 (68\%) patients with HPTH harbored pathogenic variants affecting cysteines in exons 10 or 11 . The most frequent was C634R, found in 7 of 19 patients. The other variants were found in the transmembrane domain ( $\mathrm{S} 649 \mathrm{~L}$ in one patient) or the intracellular domain (V704F in one patient, and V804M in four patients).

\section{$\underline{R E T \text { polymorphic alleles }}$}

Clinical and molecular data were analyzed according to four SNPs, i.e. G691S (rs1799939), L769L (rs1800861), S836S (rs1800862), and S904S (rs1800863), in 244 of 366 MEN2A patients with clinical information. The frequency of RET SNPs was similar to that reported in the literature, i.e. G691S 24.3\%, L769L 22.1\%, S836S 8.4\%, and S904S $19.9 \%$.

The presence of the G691S SNP was associated with a higher risk of developing PHEO ( $p=0.036)$ (Figure 3A). The same tendency was observed when in analyses of the two groups of the ATA classification « high risk » group (patient carrier of variant in 634 codon) and " moderate risk " group (patient carrier of variant other than 634), without reaching the significance threshold for both group $(p=0.07)$. However, for the patient with PHEO, statistical testing was not able to detect a difference in age at the time of molecular analysis in groups with or without G691S ( $46.7 \pm 1.5$ years with G691S and $44.3 \pm 1.0$ years without, $p=0.8$ ). We examined whether the G691S SNP would change the age at which 
PHEO might have been diagnosed according to the 3 ATA categories of pathogenic variants. No difference between the different risk levels was found.

We also examined whether the presence of one, two, three or four RET SNPs might increase the risk of PHEO. The distribution of the number of polymorphisms was significantly different between the four groups of patients $(p=0.04)$. Patients with PHEO were found to have a higher SNP number $(1.38 \pm 1.06)$ than patients without PHEO $(1.05 \pm$ 0.95) (Figure 3).

\section{DISCUSSION}

We report the rate of new cases carrying pathogenic variants or VUS in non-SNP RET per year and their distribution in the French population studied between 2003 and 2013. As recommended by INCa and based on the literature, the exons bearing activating mutations (exons 5, 8, 10,11, 13, 14, 15 and 16) were analyzed in all patients. In our 480 index cases, we found 74 different pathogenic variants or VUS non-SNP. Codon 634 was the most frequently altered codon, as already described $(18,19)$. However, the frequency spectrum of these variants is not universal and there are differences among ethnic groups, presumably caused by founder effects. For instance, in Greece, the G533C variant, with a prevalence of $36.2 \%$, appears to be characteristic of a specific ethnic group (20). This variant has rarely been found in other series $(18,19,21,22)$, and in our study the frequency amounts to only $0.6 \%$ of patients. We found $8.9 \%$ of the patients to be carriers of L790F, a pathogenic variant that seems to be present more often in Germany and Slovenia but rarely in other European countries (Supplemental Data 2) $(22,23)$. Our spectrum of $R E T$ variants is similar to that found in Germany, but quite different from that in Italy, Spain, or Greece (18-21).

The accumulation of genotype-phenotype data over the last decade has made it possible to define risk profiles, to estimate the penetrance of MEN for index cases, and to recommend the optimal age for a prophylactic thyroidectomy or PHEO and HPTH screening in asymptomatic carriers of $R E T$ pathogenic variants $(1,2,24)$. 
In our study, $92.3 \%$ of the patients carrying pathogenic $R E T$ variants received such recommendations. However, for 36 patients carrying RET variants not classified by the ATA, the data were not sufficient to support a recommendation. The majority of these patients had been diagnosed after age 30 , but two patients had been diagnosed at the age of one year and 21 years. The patient diagnosed at the age of one year had a C541R variant associated with a MEN2B-like phenotype and Hirschprung's disease. Unfortunately, there is no current available clinical data to further confirm the clinical diagnosis. This variant concerns one of the extracellular cysteine residues. The C541R variant is predicted to be deleterious by the three bioinformatics algorithms used. Based on the consensus recommendation of the ACMG for the characterization of variants, the substitution is considered as probably pathogenic. A nonsense change in codon 541 in patients with Hirschsprung's disease has been described in the literature but there is no precedence of a codon 541 variant with an activating mutation (25). The functional impact of C541R awaits confirmation by further studies. The patient diagnosed at age 21 had a V648I variant. With functional tests, this variant is qualified as having a low oncogenic potential (26), and the three bioinformatics algorithms have predicted it to be a tolerable substitution. This variant has been reported in trans with C634R for a patient with MTC and bilateral PHEO but his two children with the V648I variant had no evidence for the presence of tumors (27). Considering all these arguments, we consider this variant to be probably benign. The M918T pathogenic variant is qualified as the most aggressive variant in the ATA classification. In our study, we found another type of substitution at codon 918, i.e. $\mathrm{M} 918 \mathrm{~V}$. Although this variant was also predicted to be deleterious by the three bioinformatics algorithms used, functional testing showed that it has a low oncogenic potential (26). As reported in a recent study showing a moderate risk of MTC associated with the M918V variant, our patient was diagnosed with MTC only at age 56 (28). The M918T pathogenic substitution has been shown to modify the three-dimensional structure of the protein, creating new hydrogen bonds and stabilizing its close conformation (29, 30). Our unpublished data show that valine, a small amino acid that does not create new hydrogen bonds, does not alter the conformation of the protein. Based on these arguments, we believe that this variant is probably pathogenic. In contrast to M918T, the $\mathrm{M} 918 \mathrm{~V}$ variant is associated with a moderate risk of aggressive MTC in our patient. 
Concerning the combined mutations, each variant was classified as moderate risk by the ATA. For the concomitant presence of V804M and R844L, or K603Q and L790F, there is no clinical evidence that suggests a need for upgrading the risk from "moderate" to "high". For the patient carrying D631Y and Y791F, the diagnosis of PHEO was made earlier than in his father who carried D631Y alone. However, in the absence of information about his mother, and because of the controversy about the pathogenicity of Y791F, there is insufficient data to support a change in risk category.

Overall, we have classified nine variants as probably pathogenic and six as probably benign. It is known that MTC occurs at a variable age and aggressivity depending on the specific pathogenic variant. The clinical follow-up of these patients and further phenotypegenotype information will be required to specify the MTC risk profile. As recommended for the patients carrying pathogenic RET variants, serum calcitonin assays and ultrasound examinations can serve as an indicator for MTC in patients carrying variants not yet classified by the ATA $(1,31,32)$

Our results show that the distribution of mutations was significantly different between patients with or without PHEO. Patients with PHEO had predominantly mutations in exons 10 or 11 and these concerned cysteine residues. These tumors are known to produce catecholamines, and about one-third of the tumors are bilateral at initial diagnosis. The more dramatic clinical behavior explains why the mean age of diagnosis is lower when PHEO is the first manifestation of MEN 2A. Thus, the ATA recommended that screening for PHEO should begin by age 11 for children carrying a 634 pathogenic variant and by age 16 in children with other pathogenic variants.

The polymorphic RET alleles G691S (rs1799939), L769L (rs1800861), S836S ( $r$ 1800862), and S904S (rs1800863) have sometimes been considered as disease modifiers. The role that the RET G691S polymorphism plays in the susceptibility to MTC has been investigated and a meta-analysis based on 11 studies, combining 968 MTC cases and 2115 controls, confirms the involvement of this RET variant in MTC (15), but no involvement in risk of PHEO has been reported. In silico analysis has shown that the G691S SNP changes the phosphorylation pattern that may enhance signal transduction. 
Moreover, two functional studies $(33,34)$ have demonstrated that two pathogenic variants (S891A and K666Q), qualified as "moderate" risks according to the ATA classification, display a higher oncogenic potential when they are associated with the G691S substitution. We investigated whether G691S modifies the age at diagnosis for patients carrying pathogenic variants with low oncogenic potential, but no modifier effect was found. However, we found that the G691S variant increases the risk of PHEO independently of the 634 RET pathogenic variant. According to some studies, G691S should be described as a risk modifier in MEN2. The additive effect of RET polymorphisms on sporadic MTC and PHEO has been investigated including multiple RET variants, i.e. G691S, L769L, S836S, and S904S $(8,11)$. The results showed that three or more polymorphic alleles were not associated with age at diagnosis or tumor size, but increased the risk of lymph node and distant metastases at diagnosis of sporadic MTC. In the case of PHEO, the presence of two RET variants was associated with increased susceptibility to PHEO and age-related penetrance. We found no link between the number of SNPs and the age at diagnosis of MTC, but the susceptibility for PHEO increased. Our study is retrospective and evaluated the potential role of the 4 RET SNPs found in the 8 analyzed exons. Our results suggest that RET G691S or a combination of SNPs may affect the development of PHEO in MEN2. These results need to be confirmed by family screening to identify an intra-familial co-segregation of these SNPs with PHEO.

The main limitations of our work may be related to the retrospective nature of the collection of data from multiple centers and the heterogeneity of the observation due to the varying method of patient management over the ten-year period of the study. Moreover, it is likely that subjects carrying mutations with a low transforming activity may not have been diagnosed if they had no family histories and had not yet developed MEN2.

Finally, our results offer a more comprehensive vision of the distribution of RET variants in France and, to our knowledge, this is the first exhaustive study of RET screening over a 10-year span in France. We report the clinical description of 36 patients carrying non-ATA-classified RET variants, and classify them according to the recommendations of the ACMG. Our results suggest that RET SNPs such as G691S, or a combination of SNPs, may be associated with the development of PHEO. This finding may have significant 
implications in the management of patients, particularly for the diagnosis of PHEO in patients carrying the G691S SNP. With the advent of next-generation sequencing, comprehensive analysis of the RET exome or the entire locus may be extended to all patients with MEN2 so that phenotype-genotype correlations for rare or unknown variants could be usefully implemented for the management of patients.

\section{ACKNOWLEDGMENT}

We are grateful to Mr Kanaya Malkani and Ms Caroline Jacques for their critical reading of the manuscript.

\section{DISCLOSURE}

All authors declare that there is no conflict of interest that could be perceived as prejudicing the impartiality of the research reported.

FUNDING

This work was supported by the University Hospital of Angers, INCa, Groupes d'étude des tumeurs endocrines (GTE), OncoGENetic on NeuroEndocrine Tumors (TENGEN) Société Francaise d'endocrinologie (SFE), INSERM, CNRS.

Corresponding author: D Mirebeau-Prunier Laboratoire de Biochimie et Biologie Moléculaire, UMR CNRS 6214, INSERM U1083, CHU Angers, 4 rue Larrey, 49933 ANGERS Cedex 01, France

Mail to: deprunier@chu-angers.fr 


\section{REFERENCES}

1. Wells SA, Jr., Asa SL, Dralle H, Elisei R, Evans DB, Gagel RF, Lee N, Machens A, Moley JF, Pacini F, Raue F, Frank-Raue K, Robinson B, Rosenthal MS, Santoro M, Schlumberger M, Shah M, Waguespack SG 2015 Revised American Thyroid Association guidelines for the management of medullary thyroid carcinoma. Thyroid 25:567-610.

2. Kloos RT, Eng C, Evans DB, Francis GL, Gagel RF, Gharib H, Moley JF, Pacini F, Ringel MD, Schlumberger M, Wells SA, Jr. 2009 Medullary thyroid cancer: management guidelines of the American Thyroid Association. Thyroid 19:565-612.

3. Frank-Raue K, Rybicki LA, Erlic Z, Schweizer H, Winter A, Milos I, Toledo SP, Toledo RA, Tavares MR, Alevizaki M, Mian C, Siggelkow H, Hufner M, Wohllk N, Opocher G, Dvorakova S, Bendlova B, Czetwertynska M, Skasko E, Barontini M, Sanso G, Vorlander C, Maia AL, Patocs A, Links TP, de Groot JW, Kerstens MN, Valk GD, Miehle K, Musholt TJ, Biarnes J, Damjanovic S, Muresan M, Wuster C, Fassnacht M, Peczkowska M, Fauth C, Golcher H, Walter MA, Pichl J, Raue F, Eng C, Neumann HP 2011 Risk profiles and penetrance estimations in multiple endocrine neoplasia type 2A caused by germline RET mutations located in exon 10. Hum Mutat 32:51-58.

4. Valdes N, Navarro E, Mesa J, Casteras A, Alcazar V, Lamas C, Tebar J, Castano L, Gaztambide S, Forga L 2015 RET Cys634Arg mutation confers a more aggressive multiple endocrine neoplasia type 2A phenotype than Cys634Tyr mutation. Eur J Endocrinol 172:301-307.

5. Toledo RA, Hatakana R, Lourenco DM, Jr., Lindsey SC, Camacho CP, Almeida M, Lima JV, Jr., Sekiya T, Garralda E, Naslavsky MS, Yamamoto GL, Lazar M, Meirelles O, Sobreira TJ, Lebrao ML, Duarte YA, Blangero J, Zatz M, Cerutti JM, Maciel RM, Toledo SP 2014 Comprehensive assessment of the disputed RET Y791F variant shows no association with medullary thyroid carcinoma susceptibility. Endocr Relat Cancer 22:65-76.

6. Erlic Z, Hoffmann MM, Sullivan M, Franke G, Peczkowska M, Harsch I, Schott M, Gabbert HE, Valimaki M, Preuss SF, Hasse-Lazar K, Waligorski D, Robledo M, 
Januszewicz A, Eng C, Neumann HP 2010 Pathogenicity of DNA variants and double mutations in multiple endocrine neoplasia type 2 and von Hippel-Lindau syndrome. J Clin Endocrinol Metab 95:308-313.

7. Fugazzola L, Muzza M, Mian C, Cordella D, Barollo S, Alberti L, Cirello V, Dazzi D, Girelli ME, Opocher G, Beck-Peccoz P, Persani L 2008 RET genotypes in sporadic medullary thyroid cancer: studies in a large Italian series. Clin Endocrinol (Oxf) 69:418-425.

8. Ceolin L, Siqueira DR, Ferreira CV, Romitti M, Maia SC, Leiria L, Crispim D, AshtonProlla P, Maia AL 2012 Additive effect of RET polymorphisms on sporadic medullary thyroid carcinoma susceptibility and tumor aggressiveness. Eur J Endocrinol 166:847-854.

9. Ruiz A, Antinolo G, Fernandez RM, Eng C, Marcos I, Borrego S 2001 Germline sequence variant S836S in the RET proto-oncogene is associated with low level predisposition to sporadic medullary thyroid carcinoma in the Spanish population. Clin Endocrinol (Oxf) 55:399-402.

10. Elisei R, Cosci B, Romei C, Bottici V, Sculli M, Lari R, Barale R, Pacini F, Pinchera A 2004 RET exon 11 (G691S) polymorphism is significantly more frequent in sporadic medullary thyroid carcinoma than in the general population. J Clin Endocrinol Metab 89:3579-3584.

11. Siqueira DR, Ceolin L, Ferreira CV, Romitti M, Maia SC, Maciel LM, Maia AL 2014 Role of RET genetic variants in MEN2-associated pheochromocytoma. Eur J Endocrinol 170:821-828.

12. Wiench $M$, Wloch J, Wygoda Z, Gubala E, Oczko M, Pawlaczek A, Kula D, Lange D, Jarzab B 2004 RET polymorphisms in codons 769 and 836 are not associated with predisposition to medullary thyroid carcinoma. Cancer Detect Prev 28:231-236.

13. Berard I, Kraimps JL, Savagner F, Murat A, Renaudin K, Nicolli-Sire P, Bertrand G, Moisan JP, Bezieau S 2004 Germline-sequence variants S836S and L769L in the RE arranged during Transfection (RET) proto-oncogene are not associated with predisposition to sporadic medullary carcinoma in the French population. Clin Genet 65:150-152.

14. Gimm O, Neuberg DS, Marsh DJ, Dahia PL, Hoang-Vu C, Raue F, Hinze R, Dralle H, 
Eng C 1999 Over-representation of a germline RET sequence variant in patients with sporadic medullary thyroid carcinoma and somatic RET codon 918 mutation. Oncogene 18:1369-1373.

15. Lantieri F, Caroli F, Ceccherini I, Griseri P 2012 The involvement of the RET variant G691S in medullary thyroid carcinoma enlightened by a meta-analysis study. Int J Cancer 132:2808-2819.

16. Richards S, Aziz N, Bale S, Bick D, Das S, Gastier-Foster J, Grody WW, Hegde M, Lyon E, Spector E, Voelkerding K, Rehm HL, Committee ALQA 2015 Standards and guidelines for the interpretation of sequence variants: a joint consensus recommendation of the American College of Medical Genetics and Genomics and the Association for Molecular Pathology. Genet Med 17:405-424.

17. Eng C, Clayton D, Schuffenecker I, Lenoir G, Cote G, Gagel RF, van Amstel HK, Lips CJ, Nishisho I, Takai SI, Marsh DJ, Robinson BG, Frank-Raue K, Raue F, Xue F, Noll WW, Romei C, Pacini F, Fink M, Niederle B, Zedenius J, Nordenskjold M, Komminoth P, Hendy GN, Mulligan LM, et al. 1996 The relationship between specific RET protooncogene mutations and disease phenotype in multiple endocrine neoplasia type 2. International RET mutation consortium analysis. Jama 276:1575-1579.

18. Romei C, Mariotti S, Fugazzola L, Taccaliti A, Pacini F, Opocher G, Mian C, Castellano M, degli Uberti E, Ceccherini I, Cremonini N, Seregni E, Orlandi F, Ferolla P, Puxeddu E, Giorgino F, Colao A, Loli P, Bondi F, Cosci B, Bottici V, Cappai A, Pinna G, Persani L, Uberta V, Boscaro M, Castagna MG, Cappelli C, Zatelli MC, Faggiano A, Francia G, Brandi ML, Falchetti A, Pinchera A, Elisei R 2010 Multiple endocrine neoplasia type 2 syndromes (MEN 2): results from the ItaMEN network analysis on the prevalence of different genotypes and phenotypes. Eur J Endocrinol 163:301-308.

19. Machens A, Lorenz K, Sekulla C, Hoppner W, Frank-Raue K, Raue F, Dralle H 2013 Molecular epidemiology of multiple endocrine neoplasia 2: implications for RET screening in the new millenium. Eur J Endocrinol 168:307-314.

20. Sarika HL, Papathoma A, Garofalaki M, Saltiki K, Pappa T, Pazaitou-Panayiotou K, Anastasiou E, Alevizaki M 2015 Genetic screening of patients with medullary thyroid cancer in a referral center in Greece during the past two decades. Eur J Endocrinol 172:501-509. 
21. Fernandez RM, Navarro E, Antinolo G, Ruiz-Ferrer M, Borrego S 2006 Evaluation of the role of RET polymorphisms/haplotypes as modifier loci for MEN 2, and analysis of the correlation with the type of RET mutation in a series of Spanish patients. Int J Mol Med 17:575-581.

22. Mathiesen JS, Kroustrup JP, Vestergaard P, Stochholm K, Poulsen PL, Rasmussen AK, Feldt-Rasmussen U, Gaustadnes M, Orntoft TF, Hansen TV, Nielsen FC, Brixen K, Godballe C, Frederiksen AL 2016 Distribution of RET mutations in multiple endocrine neoplasia 2 in Denmark 1994-2014: a nationwide study. Thyroid.

23. Bergant D, Hocevar M, Besic N, Glavac D, Korosec B, Caserman S 2006 Hereditary medullary thyroid cancer in Slovenia--genotype-phenotype correlations. Wien Klin Wochenschr 118:411-416.

24. Rohmer V, Vidal-Trecan G, Bourdelot A, Niccoli P, Murat A, Wemeau JL, BorsonChazot F, Schvartz C, Tabarin A, Chabre O, Chabrier G, Caron P, Rodien P, Schlumberger M, Baudin E, Groupe Francais des Tumeurs E 2011 Prognostic factors of disease-free survival after thyroidectomy in 170 young patients with a RET germline mutation: a multicenter study of the Groupe Francais d'Etude des Tumeurs Endocrines. J Clin Endocrinol Metab 96:E509-518.

25. Yin L, Barone V, Seri M, Bolino A, Bocciardi R, Ceccherini I, Pasini B, Tocco T, Lerone M, Cywes S, et al. 1994 Heterogeneity and low detection rate of RET mutations in Hirschsprung disease. Eur J Hum Genet 2:272-280.

26. Cosci B, Vivaldi A, Romei C, Gemignani F, Landi S, Ciampi R, Tacito A, Molinaro E, Agate L, Bottici V, Cappagli V, Viola D, Piaggi P, Vitti P, Pinchera A, Elisei R 2011 In silico and in vitro analysis of rare germline allelic variants of RET oncogene associated with medullary thyroid cancer. Endocr Relat Cancer 18:603-612.

27. Nunes AB, Ezabella MC, Pereira AC, Krieger JE, Toledo SP 2002 A novel Val648Ile substitution in RET protooncogene observed in a Cys634Arg multiple endocrine neoplasia type 2A kindred presenting with an adrenocorticotropin-producing pheochromocytoma. J Clin Endocrinol Metab 87:5658-5661.

28. Martins-Costa MC, Cunha LL, Lindsey SC, Camacho CP, Dotto RP, Furuzawa GK, Sousa MS, Kasamatsu TS, Kunii IS, Martins MM, Machado AL, Martins JR, Dias-daSilva MR, Maciel RM 2016 M918V RET mutation causes familial medullary thyroid 
carcinoma: study of 8 affected kindreds. Endocr Relat Cancer 23:909-920.

29. Dixit A, Torkamani A, Schork NJ, Verkhivker G 2009 Computational modeling of structurally conserved cancer mutations in the RET and MET kinases: the impact on protein structure, dynamics, and stability. Biophys J 96:858-874.

30. Plaza-Menacho I, Barnouin K, Goodman K, Martinez-Torres RJ, Borg A, Murray-Rust J, Mouilleron S, Knowles P, McDonald NQ 2014 Oncogenic RET kinase domain mutations perturb the autophosphorylation trajectory by enhancing substrate presentation in trans. Mol Cell 53:738-751.

31. Elisei R, Romei C, Renzini G, Bottici V, Cosci B, Molinaro E, Agate L, Cappagli V, Miccoli P, Berti P, Faviana P, Ugolini C, Basolo F, Vitti P, Pinchera A 2012 The timing of total thyroidectomy in RET gene mutation carriers could be personalized and safely planned on the basis of serum calcitonin: 18 years experience at one single center. J Clin Endocrinol Metab 97:426-435.

32. Opsahl EM, Brauckhoff M, Schlichting E, Helset K, Svartberg J, Brauckhoff K, Maehle L, Engebretsen LF, Sigstad E, Groholt KK, Akslen LA, Jorgensen LH, Varhaug JE, Bjoro T 2016 A Nationwide Study of Multiple Endocrine Neoplasia Type 2A in Norway: Predictive and Prognostic Factors for the Clinical Course of Medullary Thyroid Carcinoma. Thyroid 26:1225-1238.

33. Colombo C, Minna E, Rizzetti MG, Romeo P, Lecis D, Persani L, Mondellini P, Pierotti MA, Greco A, Fugazzola L, Borrello MG 2015 The modifier role of RET-G691S polymorphism in hereditary medullary thyroid carcinoma: functional characterization and expression/penetrance studies. Orphanet J Rare Dis 10:25.

34. Borrello MG, Aiello A, Peissel B, Rizzetti MG, Mondellini P, Degl'Innocenti D, Catalano V, Gobbo M, Collini P, Bongarzone I, Pierotti MA, Greco A, Seregni E 2011 Functional characterization of the MTC-associated germline RET-K666E mutation: evidence of oncogenic potential enhanced by the G691S polymorphism. Endocr Relat Cancer 18:519-527. 
35. Fitze G, Cramer J, Ziegler A, Schierz M, Schreiber M, Kuhlisch E, Roesner D, Schackert HK 2002 Association between c135G/A genotype and RET protooncogene germline mutations and phenotype of Hirschsprung's disease. Lancet 359:1200-1205.

36. Muzza M, Cordella D, Bombled J, Bressac-de Paillerets B, Guizzardi F, Francis Z, Beck-Peccoz P, Schlumberger M, Persani L, Fugazzola L 2010 Four novel RET germline variants in exons 8 and 11 display an oncogenic potential in vitro. Eur J Endocrinol 162:771-777.

37. Vandenbosch K, Renard M, Uyttebroeck A, Sciot R, Matthijs G, Legius E 2005 Medullary thyroid carcinoma in a child with a new RET mutation and a RET polymorphism. Genet Couns 16:95-100.

38. Maschek W, Pichler R, Rieger R, Weinhausel A, Berg J 2002 A new identified germline mutation of the RET proto-oncogene responsible for familial medullary thyroid carcinoma in co-existence with a hyperfunctioning autonomous nodule. Clin Endocrinol (Oxf) 56:823.

39. Nakao KT, Usui T, Ikeda M, Mori Y, Yamamoto T, Kawashima ST, Nanba K, Yuno A, Tamanaha T, Tagami T, Naruse M, Asato R, Shimatsu A 2013 Novel tandem germline RET proto-oncogene mutations in a patient with multiple endocrine neoplasia type 2B: report of a case and a literature review of tandem RET mutations with in silico analysis. Head Neck 35:E363-368.

40. So MT, Leon TY, Cheng G, Tang CS, Miao XP, Cornes BK, Diem NN, Cui L, Ngan ES, Lui VC, Wu XZ, Wang B, Wang H, Yuan ZW, Huang LM, Li L, Xia H, Zhu D, Liu J, Nguyen TL, Chan IH, Chung PH, Liu XL, Zhang R, Wong KK, Sham PC, Cherny SS, Tam PK, Garcia-Barcelo MM 2011 RET mutational spectrum in Hirschsprung disease: evaluation of 601 Chinese patients. PLoS One 6:e28986.

41. Ruiz-Ferrer M, Fernandez RM, Antinolo G, Lopez-Alonso M, Eng C, Borrego S 2006 A complex additive model of inheritance for Hirschsprung disease is supported by both RET mutations and predisposing RET haplotypes. Genet Med 8:704-710.

42. Elisei R, Cosci B, Romei C, Agate L, Piampiani P, Miccoli P, Berti P, Basolo F, Ugolini C, Ciampi R, Nikiforov Y, Pinchera A 2004 Identification of a novel point mutation in 
the RET gene (Ala883Thr), which is associated with medullary thyroid carcinoma phenotype only in homozygous condition. J Clin Endocrinol Metab 89:5823-5827.

43. Bartsch DK, Hasse C, Schug C, Barth P, Rothmund M, Hoppner W 2000 A RET double mutation in the germline of a kindred with FMTC. Exp Clin Endocrinol Diabetes 108:128-132.

44. Xu JY, Grubbs EG, Waguespack SG, Jimenez C, Gagel RF, Sosa JA, Sellin RV, Dadu R, Hu MI, Trotter CS, Jackson M, Rich TA, Hyde SM, Sherman SI, Cote GJ 2016 Medullary Thyroid Carcinoma Associated with Germline RETK666N Mutation. Thyroid 26:1744-1751. 
Table 1: RET molecular analysis performed and patient carriers of RET germline non-SNP pathogenic variants or VUS found in France for index cases or screened relatives (2003-2013).

\begin{tabular}{|c|c|c|c|c|c|c|c|c|c|c|c|c|}
\hline & 2003 & 2004 & 2005 & 2006 & 2007 & 2008 & 2009 & 2010 & 2011 & 2012 & 2013 & \begin{tabular}{|c|} 
Total \\
$2003-2013$ \\
\end{tabular} \\
\hline Total Index Cases MEN2 (N) & 894 & 454 & 386 & 383 & 449 & 492 & 429 & 390 & 378 & 385 & 469 & 5109 \\
\hline Patient with RET variants (N) & 66 & 42 & 40 & 47 & 55 & 43 & 43 & 56 & 24 & 42 & 56 & 514 \\
\hline$\%$ & $7,4 \%$ & $9,3 \%$ & $10,4 \%$ & $12,3 \%$ & $12,2 \%$ & $8,7 \%$ & $10,0 \%$ & $14,4 \%$ & $6,3 \%$ & $10,9 \%$ & $11,9 \%$ & $10,1 \%$ \\
\hline screened relatives $(\mathrm{N})$ & 217 & 264 & 203 & 200 & 205 & 206 & 179 & 210 & 147 & 150 & 233 & 2214 \\
\hline Screened relatives with RET variants (N) & 87 & 106 & 81 & 83 & 51 & 86 & 57 & 77 & 75 & 63 & 101 & 867 \\
\hline$\%$ & $40,1 \%$ & $40,1 \%$ & $40,0 \%$ & $41,5 \%$ & $24,9 \%$ & $41,7 \%$ & $31,8 \%$ & $36,7 \%$ & $51,0 \%$ & $42,0 \%$ & $43,3 \%$ & $39,1 \%$ \\
\hline Total Patient with RET variants (N) & 153 & 148 & 121 & 130 & 106 & 129 & 100 & 133 & 99 & 105 & 157 & 1381 \\
\hline
\end{tabular}

Report completed by the INCa each year for index cases and screened relatives 
Table 2: Rare RET VUS non-SNP variants non ATA-classified: clinical feature, population database report, in silico predictive algorithms and proposition of classification following

ACMG

\begin{tabular}{|c|c|c|c|c|c|c|c|c|c|c|c|c|c|}
\hline Exon & genotype & Protein change & N Patient & $\begin{array}{l}\text { dbSNP/NCBI database } \\
\text { (Number of report) }\end{array}$ & $\begin{array}{c}\text { ExAC } \\
\text { (frequency) }\end{array}$ & SIFT & Polyphen2 & \begin{tabular}{|c} 
Mutation \\
Taster
\end{tabular} & \begin{tabular}{|l|} 
oncogenic \\
potential in vitro \\
(references)
\end{tabular} & \begin{tabular}{|l} 
Age at \\
diagnosis
\end{tabular} & $\begin{array}{l}\begin{array}{l}\text { Clinical } \\
\text { phénotype }\end{array} \\
\end{array}$ & References & $\begin{array}{l}\text { Classification } \\
\text { following ACMG }\end{array}$ \\
\hline \multicolumn{14}{|c|}{ SINGLE VARIANTS (missense) } \\
\hline 5 & $c .0884 \mathrm{C}>\mathrm{T}$ & T295M & 1 & not reported & $8.765 \mathrm{e}-06$ & $T$ & $T$ & $T$ & & 49 & MTC & & VUS \\
\hline 5 & c. $1013 \mathrm{C}>\mathrm{T}$ & T3381 & 1 & rs3777767433 (3) & $4.32 \mathrm{e}-05$ & $T$ & $T$ & $\mathrm{~T}$ & low or No (26) & 42 & ND & $18-26-35$ & vus \\
\hline \multirow[t]{2}{*}{8} & c.1529 C>T & A510V & 2 & rs201745826(5) & 0.0003 & $T$ & $T$ & $\mathrm{~T}$ & potential (36) & 75 & ND & 36 & vus \\
\hline & & & & & & & & & & 69 & MTC & & \\
\hline \multirow[t]{2}{*}{8} & c. $1531 \mathrm{G}>\mathrm{A}$ & E511K & 2 & rs201553718 (8) & 0.0002 & $T$ & $T$ & D & potential (36) & 73 & MTC & 36 & vus \\
\hline & & & & & & & & & & 38 & MTC & & \\
\hline 8 & $\begin{array}{l}c .1544 G>T \\
\end{array}$ & C515F & 1 & not reported & not reported & D & D & D & & 49 & MTC & & likely pathogenic \\
\hline \multirow[t]{2}{*}{8} & c.1591T>C & C531R & 2 & rs3777767390 (1) & not reported & D & P & D & potential (36) & 59 & MTC & 36 & likely pathogenic \\
\hline & & & & & & & & & & 58 & MTC & & \\
\hline 8 & \begin{tabular}{|l}
$.1621 T>C$ \\
\end{tabular} & C541R & 1 & not reported & not reported & D & D & D & & 0,12 & \begin{tabular}{|l|} 
MEN2B- \\
Hirsprung
\end{tabular} & & likely pathogenic \\
\hline \multirow[t]{2}{*}{8} & c.1642G>A & G548S & 2 & rs374461212 (3) & $4.555 \mathrm{e}-05$ & $T$ & D & D & & 53 & MTC and PHEO & & VUS \\
\hline & & & & & & & & & & 53 & MTC & & \\
\hline 11 & c.1930T>G & F644V & 1 & not reported & not reported & $T$ & $T$ & D & & 35 & MTC & & VUS \\
\hline \multirow[t]{3}{*}{11} & $\begin{array}{l}c .1942 \mathrm{G}>\mathrm{A} \\
\end{array}$ & \begin{tabular}{|l|l|} 
V6481 & \\
\end{tabular} & 3 & rs $77711105(6)$ & $9.076 \mathrm{e}-05$ & $T$ & $T$ & $T$ & low or No (26) & 65 & MTC & $26-27$ & Likely benign \\
\hline & & & & & & & & & & 68 & MTC & & \\
\hline & & & & & & & & & & 21 & MTC & & \\
\hline 11 & c. $1997 \mathrm{~A}>\mathrm{C}$ & K666T & 1 & rs377767439 (2) & $8.242 \mathrm{e}-06$ & D & D & D & & 41 & MTC and Pheo & & likely pathogenic \\
\hline \multirow[t]{2}{*}{11} & \begin{tabular}{|l|} 
c.1998delinst \\
TCT
\end{tabular} & & 2 & rs3777767440 (1) & $8.242 \mathrm{e}-06$ & $T$ & D & D & & 35 & ND & 37 & likely pathogenic \\
\hline & & & & & & & & & & 58 & MTC & & likely pathogenic \\
\hline 11 & c. $1998 \mathrm{G}>\mathrm{C}$ & K666N & 1 & rs146646971(5) & not reported & $T$ & D & D & & 63 & MTC & 36 & likely pathogenic \\
\hline 11 & c.1998G >T & K666N & 1 & rs146646971 (5) & $2.473 \mathrm{e}-05$ & $T$ & D & D & potential (36) & 59 & MTC & $36-44$ & likely pathogenic \\
\hline \begin{tabular}{|l|}
11 \\
\end{tabular} & c.2110G>T & \begin{tabular}{|l|l|} 
V704F \\
\end{tabular} & 1 & not reported & not reported & $T$ & D & D & & 49 & HPT & & vUS \\
\hline 13 & c. $2342 \mathrm{~A}>\mathrm{G}$ & Q781R & 1 & rs3377767416 (2) & not reported & D & D & D & & 73 & MTC & $38-39$ & vus \\
\hline 13 & C. $2348 \mathrm{~A}>\mathrm{G}$ & N783S & 1 & not reported & not reported & D & D & D & & 57 & MTC & 40 & Vus \\
\hline 13 & c.2371T>A & Y791N & 1 & rs3777767417 (3) & $2.503 \mathrm{e}-05$ & D & $\mathrm{P}$ & $\mathrm{D}$ & & 58 & MTC and CCH & 41 & vus \\
\hline 15 & c. $2647 \mathrm{G}>\mathrm{A}$ & A883T & 1 & rs377767428 (1) & not reported & $T$ & D & D & & 68 & MTC & 42 & likely pathogenic \\
\hline 15 & c.2657G>A & $\mathrm{R} 886 \mathrm{Q}$ & 1 & rs373594744 (1) & $3.377 \mathrm{e}-05$ & $T$ & D & $\mathrm{D}$ & & 84 & ND & & vus \\
\hline 16 & $c .2752 \mathrm{~A}>\mathrm{G}$ & M918V & 1 & rs3777767442(1) & not reported & D & D & D & Iow or No (26) & 56 & MTC & $26-28$ & likely pathogenic \\
\hline \multicolumn{14}{|c|}{ SINGLE VARIANTS (synonymous) } \\
\hline \multirow[t]{2}{*}{8} & c.1539G>A & A513A & 1 & rs761430718 (1) & $8.271 \mathrm{e}-06$ & & & & & 60 & MTC & & Likely benign \\
\hline & c. $1860 \mathrm{C}>\mathrm{T}$ & c620C & 1 & not reported & not reported & & & & & 70 & MTC and PHEO & & Likely benign \\
\hline \multirow[t]{3}{*}{11} & $c .2037 C>T$ & P679P & 1 & rs55862116 (9) & $1.128 \mathrm{e}-03$ & & & & & 45 & MTC & & Likely benign \\
\hline & c. $2052 \mathrm{G}>\mathrm{A}$ & P648P & 1 & rs145122337 (2) & $2.718 \mathrm{e}-04$ & & & & & 75 & MTC & & Likely benign \\
\hline & c. $2097 \mathrm{C}>\mathrm{T}$ & S6995 & 1 & not reported & not reported & & & & & 62 & MTC & & Likely benign \\
\hline \multicolumn{14}{|c|}{ DOUBLE VARIANTS } \\
\hline $14 ; 14$ & $\begin{array}{l}\text { c. }[2410 \mathrm{G}>\mathrm{A} \\
\text { (;)c.2531G>T] }\end{array}$ & $\begin{array}{l}{[\mathrm{V} 804 \mathrm{M}(;) \mathrm{R} 844 \mathrm{~L}} \\
]\end{array}$ & 1 & & & & & & & 51 & MTC & 43 & Pathogenic \\
\hline $10 ; 13$ & $\begin{array}{l}\text { c. [1807 A>C } \\
\text { (;) c.2370 } \\
G>T]\end{array}$ & [K603Q(;)L790F] & 1 & & & & & & & 60 & MTC & & Pathogenic \\
\hline $\mid 11 ; 13$ & $\begin{array}{l}\text { c. }[1891 \mathrm{G}>\mathrm{T}(;) \mathrm{c} \\
.2372 \mathrm{~A}>\mathrm{T}]\end{array}$ & [D631Y(;)Y791F] & 1 & & & & & & & 31 & MTC and PHEO & & $\mid$ Pathogenic \\
\hline
\end{tabular}




\section{FIGURE LEGENDS}

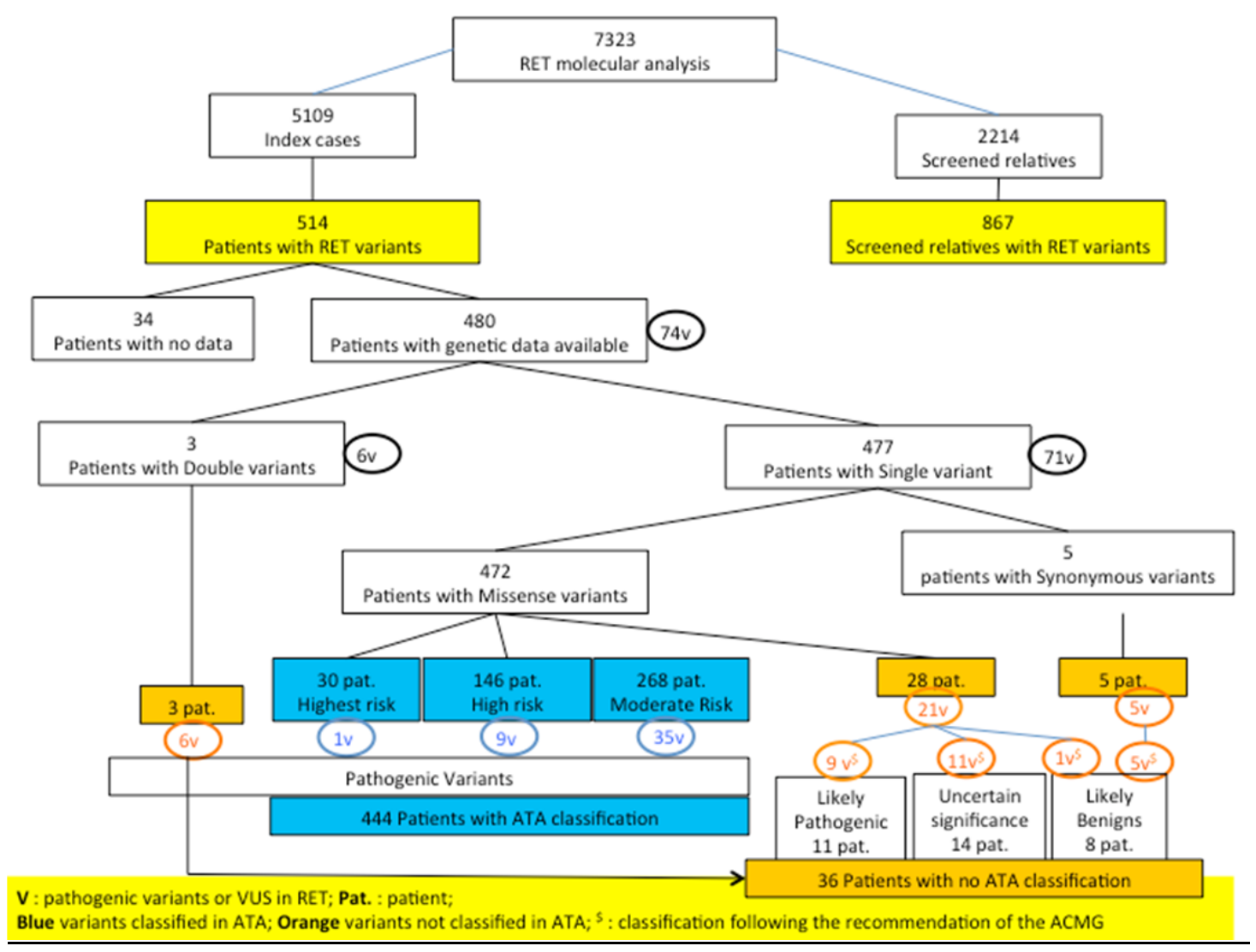

Figure 1 :_Pathogenic variants or VUS in_RET for index cases and screened relatives from

2003 to 2013. Classification by risk groups following the 2015 ATA clinical Guidelines for MTC and proposition of classifying variants not found in the Guidelines following the consensus recommendation of the ACMG. 
A

\begin{tabular}{|c|c|c|c|c|c|c|}
\hline \multicolumn{7}{|c|}{ Age at first diagnosis: years (Mean \pm sd) } \\
\hline & & \multicolumn{2}{|c|}{ Patients with pheochromocytoma } & \multicolumn{2}{|c|}{ Patients without pheochromocytoma } & \multirow[t]{2}{*}{$\begin{array}{c}P \\
\text { (student's t-test) }\end{array}$} \\
\hline & $\mathrm{N}$ & & $\mathrm{N}$ & & $\mathrm{N}$ & \\
\hline Patients with MEN2A & 366 & $41.8 \pm 13.0$ & 71 & $48.7 \pm 16.3$ & 295 & 0.001 \\
\hline $\begin{array}{l}\text { Patients with } \\
\text { mutation in codon } \\
634\end{array}$ & 112 & $38.6 \pm 14.5$ & 55 & $39.8 \pm 11.0$ & 57 & 0.376 \\
\hline Cys634Arg & 43 & $36.96 \pm 12.18$ & 24 & $39.08 \pm 12.70$ & 19 & \\
\hline Cys634Tyr & 33 & $42.10 \pm 11.03$ & 15 & $37.36 \pm 18.09$ & 18 & \\
\hline Cys634Trp & 11 & $38.93 \pm 10.40$ & 6 & $39.50 \pm 11.95$ & 5 & \\
\hline Cys634Ser & 11 & $49.69 \pm 6.43$ & 5 & $42.65 \pm 13.58$ & 6 & \\
\hline Cys634Gly & 6 & $39.73 \pm 2.17$ & 3 & $40.80 \pm 7.67$ & 3 & \\
\hline Cys634Phe & 6 & 35.03 & 1 & $37.26 \pm 19.47$ & 5 & \\
\hline Cys634Leu & 2 & 35.85 & 1 & 21.54 & 1 & \\
\hline
\end{tabular}

\section{B}

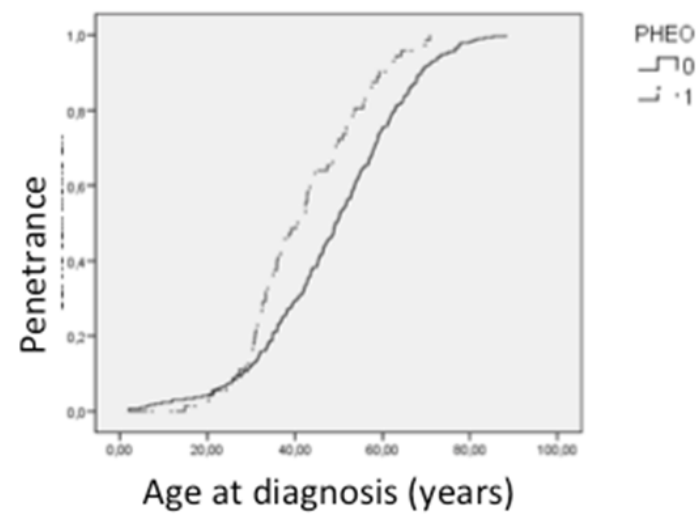

Figure 2: Patients with MEN2A carrying RET germline pathogenic variants or VUS nonSNP variants ( $\mathbf{N = 3 6 6}$ Index cases). (A) Age at the time of MEN2A diagnosis according to the presence or absence of PHEO for 366 patients and for 112 patients with a RET 634 variant. Student's-t-test was used to compare mean of age. (B) Age-related penetrance of MEN2A according to the presence or absence of PHEO for 366 patients. Kaplan-Meier estimates for the proportion of MEN2 patients who developed PHEO. The log-rank test was used to compare curves. 
A

\begin{tabular}{|c|c|c|c|}
\hline SNP & $\begin{array}{c}\text { Patients with pheochromocytoma } \\
(\mathrm{n}=53)\end{array}$ & $\begin{array}{c}\text { Patients without pheochromocytoma } \\
(\mathbf{n}=191)\end{array}$ & $\begin{array}{c}\mathbf{p} \\
(\text { Fisher Chi } \\
\text { Square test) }\end{array}$ \\
\hline G691S & 26 & 63 & 0.036 \\
\hline L769L & 23 & 58 & 0.098 \\
\hline S836S & 7 & 24 & 1 \\
\hline S904S & 17 & 56 & 0.730 \\
\hline
\end{tabular}

\begin{tabular}{|c|c|c|c|}
\hline Number of SNPs per Patient & $\begin{array}{c}\text { Patients with pheochromocytoma } \\
(\mathbf{n}=53)\end{array}$ & $\begin{array}{c}\text { atients without pheochromocytoma } \\
(\mathbf{n}=191)\end{array}$ & $\begin{array}{c}\mathrm{p} \\
(\text { student test) }\end{array}$ \\
\hline None & 14 & 74 & \\
\hline One & 13 & 45 & \\
\hline Two & 19 & 61 & \\
\hline Three & 6 & 10 & \\
\hline Four & 1 & 1 & 0.004 \\
\hline Mean 5 sd of SNP & $1.38 \pm 1.06$ & $1.05 \pm 0.95$ & \\
\hline
\end{tabular}

B

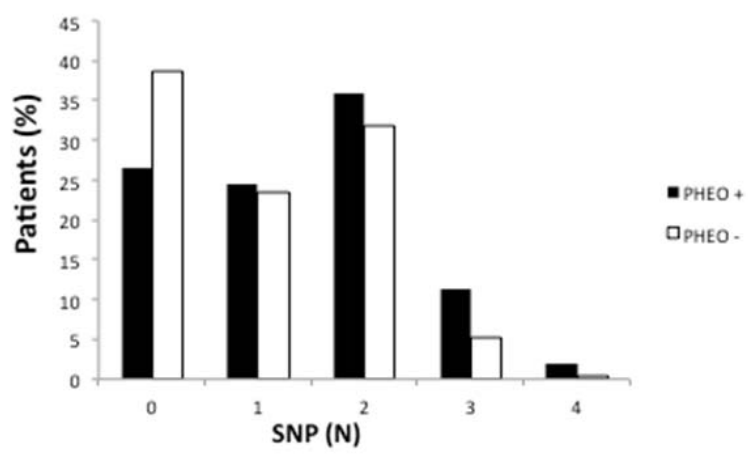

Figure 3 : Additive effect of $R E T$ polymorphisms on PHEO in patients with MEN2A (N=244 index cases). (A) Distribution of each of the four studied SNPs, i.e. G691S (rs1799939), L769L (rs1800861), S836S (rs1800862), and S904S (rs1800863) and number of SNP per MEN2A patient according to the presence or absence of PHEO. (B) Proportion of MEN2A patients with zero, one, two, three or four SNPs according to the presence or absence of PHEO. 
Supplemental data 1: RET pathogenic variants or VUS found in France between

\section{3 and 2013 in index cases.}

\begin{tabular}{|c|c|c|c|c|c|c|c|c|c|}
\hline Exon & $N(\%)$ & type of chan & genotype & $N(\%)$ & codon & $\mathrm{N}(\%)$ & Protein change & \begin{tabular}{|l} 
ATA risk level \\
(2015)
\end{tabular} & \begin{tabular}{|l|} 
ATA risk level \\
$(2009)$
\end{tabular} \\
\hline 5 & $2(0,4)$ & & & & & & & & \\
\hline 5 & & substitution & $\mathrm{C} .0884 \mathrm{C}>\mathrm{T}$ & $1(0,2)$ & 295 & $1(0,2)$ & T295M & Not classified & \\
\hline 5 & & substitution & c.1013C>T & $1(0,2)$ & 338 & $1(0,2)$ & T3381 & Not classified & \\
\hline 8 & $17(3,5)$ & & & & & & & & \\
\hline 8 & & substitution & $C .1529 \mathrm{C}>\mathrm{T}$ & $2(0,4)$ & 510 & $2(0,4)$ & A510V & Not classified & \\
\hline 8 & & \begin{tabular}{|l|} 
substitution \\
\end{tabular} & c.1531G>A & $2(0,4)$ & 511 & $2(0,4)$ & E511K & Not classified & \\
\hline 8 & & substitution & c. $1543 \mathrm{~T}>\mathrm{A}$ & $3(0,6)$ & 515 & $4(0,8)$ & C515s & Moderate risk & A \\
\hline 8 & & substitution & c. $1544 \mathrm{G}>\mathrm{T}$ & $1(0,2)$ & 515 & & C515F & Not classified & \\
\hline 8 & & substitution & c.1591T $>C$ & $2(0,4)$ & 531 & $2(0,4)$ & C531R & Not classified & \\
\hline 8 & & dup & c.1594dupAGGAGTGTG & $1(0,2)$ & $529-531$ & $1(0,2)$ & $\begin{array}{l}531 / 9 \text { base pair } \\
\text { duplication }\end{array}$ & Moderate risk & A \\
\hline 8 & & substitution & c.1597G $>\mathrm{T}$ & $3(0,6)$ & 533 & $3(0,6)$ & G533C & Moderate risk & A \\
\hline 8 & & substitution & c. $1621 T>C$ & $1(0,2)$ & 541 & $1(0,2)$ & C541R & Not classified & \\
\hline 8 & & substitution & c. $1642 \mathrm{G}>\mathrm{A}$ & $2(0,4)$ & 548 & $2(0,4)$ & G548S & Not classified & \\
\hline 10 & $78(16,2)$ & & & & & & & & \\
\hline 10 & & substitution & c.1807A $>C$ & $1(0,2)$ & 603 & $1(0,2)$ & K603E & Moderate risk & A \\
\hline 10 & & substitution & c. $1826 \mathrm{G}>\mathrm{A}$ & $3(0,6)$ & 609 & $5(1,0)$ & C609Y & Moderate risk & B \\
\hline 10 & & substitution & c. $1826 \mathrm{G}>\mathrm{T}$ & $1(0,2)$ & & & C609F & Moderate risk & B \\
\hline 10 & & substitution & c. $1827 \mathrm{C}>\mathrm{G}$ & $1(0,2)$ & & & C609W & Moderate risk & B \\
\hline$\frac{10}{10}$ & & \begin{tabular}{|l|} 
substitution \\
\end{tabular} & $c .1831 \mathrm{~T}>\mathrm{G}$ & \begin{tabular}{|l|}
$2(0,4)$ \\
$20,4)$
\end{tabular} & 611 & $12(2,5)$ & C611G & Moderate risk & \begin{tabular}{|l}
$\mathrm{D}$ \\
\end{tabular} \\
\hline 10 & & \begin{tabular}{|l} 
substitution \\
\end{tabular} & c. $1832 \mathrm{G}>\mathrm{A}$ & \begin{tabular}{|l}
$2(1,4)$ \\
$7(1,5)$
\end{tabular} & & & C611Y & \begin{tabular}{|l} 
Moderate risk \\
\end{tabular} & B \\
\hline 10 & & substitution & c. $1833 \mathrm{C}>\mathrm{G}$ & $3(0,6)$ & & & C611W & Moderate risk & B \\
\hline 10 & & substitution & c. $1852 \mathrm{~T}>\mathrm{A}$ & $12(2,5)$ & 618 & $29(6,0)$ & C618S & Moderate risk & B \\
\hline 10 & & substitution & c. $1852 \mathrm{~T}>\mathrm{C}$ & $6(1,2)$ & & & C618R & Moderate risk & B \\
\hline$\frac{10}{10}$ & & substitution & c.1853G>A & $1(0,2)$ & & & C618Y & Moderate risk & B \\
\hline$\frac{10}{10}$ & & substitution & c. $1853 \mathrm{G}>\mathrm{C}$ & \begin{tabular}{|l|} 
\\
$8(1,7)$
\end{tabular} & & & C618S & Moderate risk & B \\
\hline 10 & & substitution & c. $1853 \mathrm{G}>\mathrm{T}$ & $1(0,2)$ & & & C618F & Moderate risk & B \\
\hline 10 & & substitution & c. $1854 \mathrm{C}>\mathrm{G}$ & $1(0,2)$ & & & C618W & Moderate risk & B \\
\hline 10 & & substitution & c. $1858 \mathrm{~T}>\mathrm{C}$ & $10(2,1)$ & 620 & $31(6,4)$ & C620R & Moderate risk & B \\
\hline 10 & & \begin{tabular}{|l|} 
substitution \\
\end{tabular} & c.1858T>G & $5(1,0)$ & & & C620G & Moderate risk & B \\
\hline$\frac{10}{10}$ & & \begin{tabular}{|l|} 
substitution \\
\end{tabular} & c.1859 G>A & \begin{tabular}{|l|}
$8(1,7)$ \\
\end{tabular} & & & $\begin{array}{ll} \\
\mathrm{C} 620 \mathrm{Y}\end{array}$ & Moderate risk & \begin{tabular}{|l}
$\mathrm{D}$ \\
\end{tabular} \\
\hline 10 & & substitution & c. $1859 \mathrm{G}>\mathrm{C}$ & $1(0,2)$ & & & C620S & Moderate risk & B \\
\hline 10 & & substitution & c. $1859 \mathrm{G}>\mathrm{T}$ & $3(0,6)$ & & & C62OF & Moderate risk & B \\
\hline 10 & & substitution & c. $1860 \mathrm{C}>\mathrm{G}$ & \begin{tabular}{|l|}
$4(0,8)$ \\
\end{tabular} & & & C620W & Moderate risk & B \\
\hline 11 & $158(32,9)$ & & & & & & & & \\
\hline 111 & & substitution & C.1888 T>C & $1(0,2)$ & 1630 & $11(0,2)$ & C630R & Moderate risk & B \\
\hline 11 & & substitution & c. $1900 \mathrm{~T}>\mathrm{A}$ & $12(2,5)$ & 634 & $144(29,9)$ & C634S & High risk & C \\
\hline 11 & & substitution & c. $1900 \mathrm{~T}>\mathrm{C}$ & $53(11,0)$ & & & C634R & High risk & C \\
\hline 11 & & substitution & c. $1900 \mathrm{~T}>\mathrm{G}$ & $7(1,5)$ & & & C634G & High risk & C \\
\hline$\frac{11}{11}$ & & delins & c.1901_1902delGCinsTG & $2(0,4)$ & & & C634L & High risk & B \\
\hline$\frac{11}{11}$ & & substitution & c.1901G>A & $46(9,5)$ & & & C634Y & High risk & C \\
\hline$\frac{11}{11}$ & & substitution & c. $1901 \mathrm{G}>\mathrm{C}$ & $3(0,6)$ & & & C634S & High risk & C \\
\hline 11 & & substitution & c. $1901 \mathrm{G}>\mathrm{T}$ & $9(1,9)$ & & & C634F & High risk & C \\
\hline 11 & & substitution & c. $1902 C>G$ & $12(2,5)$ & & & C634W & High risk & c \\
\hline 11 & & substitution & c. $1930 \mathrm{~T}>\mathrm{G}$ & $1(0,2)$ & 644 & $1(0,2)$ & F644V & Not classified & \\
\hline$\frac{11}{11}$ & & substitution & c.1942G>A & \begin{tabular}{|l|l|}
$3(0,6)$ \\
$(0,2)$
\end{tabular} & $\frac{648}{648}$ & $\frac{10,21}{3(0,6)}$ & V648I & Not classified & \\
\hline 11 & & substitution & c. $1946 \mathrm{C}>\mathrm{t}$ & \begin{tabular}{|l|l|}
$2(0,4)$ \\
\end{tabular} & 649 & $2(0,4)$ & S649L & Moderate risk & A \\
\hline 11 & & substitution & c.1996A>G & $1(0,2)$ & 666 & $7(1,5)$ & K666E & Moderate risk & A \\
\hline 11 & & substitution & c. $1997 \mathrm{~A}>\mathrm{C}$ & $1(0,2)$ & & & K666T & Not classified & \\
\hline$\frac{11}{11}$ & & substitution & C. $1998 \mathrm{G}>\mathrm{C}$ & $\frac{10,21}{1(0,2)}$ & & & K666N & Not classified & \\
\hline 11 & & delins & c.1998delinsTTCT & $\mid$\begin{tabular}{|l|l|}
$2(0,4)$ \\
\end{tabular} & & & K666 & Not classified & \\
\hline$\frac{11}{11}$ & & substitution & c.1998G $>T$ & $1(0,2)$ & & & K666N & Not classified & \\
\hline 11 & & substitution & $c .2110 \mathrm{G}>\mathrm{T}$ & $1(0,2)$ & 704 & $1(0,2)$ & V704F & Not classified & \\
\hline 13 & $66(13,7)$ & & & & & & & & \\
\hline 13 & & substitution & c. $2304 \mathrm{G}>\mathrm{C}$ & $10(2,1)$ & 768 & $14(2,9)$ & E768D & Moderate risk & $\overline{\mid A}$ \\
\hline$\frac{13}{13}$ & & \begin{tabular}{|l|} 
substitution \\
\end{tabular} & c.2304G $>\mathrm{T}$ & $4(0,8)$ & & & E768D & Moderate risk & $A^{A}$ \\
\hline 13 & & substitution & c. $2342 A>G$ & $1(0,2)$ & 781 & $1(0,2)$ & Q781R & Not classified & \\
\hline 13 & & substitution & C.2350A $>\mathrm{G}$ & $1(0,2)$ & 783 & $1(0,2)$ & N783S & Not classified & \\
\hline 13 & & substitution & c. $2370 \mathrm{G}>\mathrm{C}$ & $5(1,0)$ & 790 & $43(8,9)$ & L790F & Moderate risk & A \\
\hline 13 & & substitution & c. $2370 \mathrm{G}>\mathrm{T}$ & $38(7,9)$ & & & L790F & Moderate risk & A \\
\hline$\frac{15}{13}$ & & substitution & c.2371T >A & $1(0,2)$ & 791 & $7(1,5)$ & Y791N & Not classified & \\
\hline$\frac{13}{13}$ & & \begin{tabular}{|l|} 
substitution \\
\end{tabular} & c. $2372 \mathrm{~A}>\mathrm{T}$ & $\mid \frac{110,21}{6(1,2)}$ & & & Y791F & Moderate risk & A \\
\hline 14 & $95(19,8)$ & & & & & & & & \\
\hline 14 & & substitution & $\mathrm{c} .2410 \mathrm{G}>\mathrm{A}$ & $83(17,2)$ & 804 & $95(19,7)$ & V804M & Moderate risk & IA \\
\hline$\frac{14}{14}$ & & substitution & c. $2410 \mathrm{G}>\mathrm{C}$ & $\frac{03(11,2}{3(0,6)}$ & & & V804L & Moderate risk & $\frac{A}{A}$ \\
\hline 14 & & substitution & c. $2410 \mathrm{G}>\mathrm{T}$ & $9(1,9)$ & & & V804L & Moderate risk & A \\
\hline 15 & $24(5,0)$ & & & & & & & & \\
\hline 15 & & substitution & c.2647_2648delGCinsTT & $2(0,4)$ & 883 & $3(0,6)$ & A883F & High risk & D \\
\hline$\frac{15}{15}$ & & substitution & c. $2647 \mathrm{G}>\mathrm{A}$ & $1(0,2)$ & & & A883T & Not classified & \\
\hline 15 & & substitution & $c .2657 \mathrm{G}>\mathrm{A}$ & $1(0,2)$ & 886 & $1(0,2)$ & R886Q & Not classified & \\
\hline$\frac{15}{15}$ & & substitution & c.2670T>G & $\mid \frac{1}{20}(4,1)$ & 891 & $\mid \begin{array}{l}20(4,1) \\
20,1\end{array}$ & S891A & Moderate risk & A \\
\hline 16 & $32(6,7)$ & & & & & & & & \\
\hline 16 & & substitution & c. $2735 \mathrm{G}>\mathrm{C}$ & $1(0,2)$ & 912 & $1(0,2)$ & R912P & Moderate risk & $\bar{A}$ \\
\hline$\frac{10}{16}$ & & substitution & c. $2752 A>G$ & $1(0,2)$ & 918 & $30(6,2)$ & M918V & Not classified & \\
\hline 16 & & substitution & c. $2753 \mathrm{~T}>\mathrm{C}$ & $30(6,0)$ & & & M918T & Highest risk & $\mathrm{D}$ \\
\hline \begin{tabular}{|l} 
Double \\
variants
\end{tabular} & $3(0,8)$ & & & & & & & & \\
\hline $10 ; 13$ & & double & c. $[1807 \mathrm{~A}>\mathrm{C}(;)$ c. $2370 \mathrm{G}>\mathrm{T}]$ & $1(0,2)$ & $603-790$ & $1(0,2)$ & K603Q;L79OF & Not classified & \\
\hline $11 ; 13$ & & double & c. $[1891 \mathrm{G}>\mathrm{T}(;)$ c. $2372 \mathrm{~A}>\mathrm{T}]$ & $\frac{1}{1(0,2)}$ & $631-791$ & $1(0,2)$ & D631Y;Y791F & Not classified & \\
\hline $14 ; 14$ & & double & c. $[2410 \mathrm{G}>\mathrm{A}(;) \mathrm{s} .2531 \mathrm{G}>\mathrm{T}]$ & $1(0,2)$ & $804-844$ & $2(0,4)$ & V804M;R844L & Not classified & \\
\hline synonymous & $5(1,0)$ & & & & & & & & \\
\hline$\frac{8}{8}$ & & substitution & c.1539G $>A$ & $1(0,2)$ & 513 & $1(0,2)$ & A513A & Not classified & \\
\hline $\begin{array}{l}0 \\
10\end{array}$ & & \begin{tabular}{|l} 
substitution \\
\end{tabular} & c. $1860 \mathrm{C}>\mathrm{T}$ & \begin{tabular}{|l|l|l|l|l|}
$1(0,2)$ \\
\end{tabular} & $\frac{315}{620}$ & $\frac{1(0,2)}{1(0,2)}$ & \begin{tabular}{|l|l|}
$\mathrm{C} 613 \mathrm{~A}$ \\
$\mathrm{C}$
\end{tabular} & Not classified & \\
\hline$\frac{10}{11}$ & & \begin{tabular}{|l|} 
substitution \\
\end{tabular} & $c .2037 C>T$ & $\frac{10,21}{1(0,2)}$ & 679 & $1(0,2)$ & P679P & Not classified & \\
\hline & & substitution & c. $2052 \mathrm{G}>\mathrm{A}$ & $1(0,2)$ & 684 & $2(0,4)$ & P684P & Not classified & \\
\hline & & substitution & $\begin{array}{l}\mathrm{C} .2097 \mathrm{C}>\mathrm{T} \\
\end{array}$ & $1(0,2)$ & 699 & $1(0,2)$ & S699S & Not classified & \\
\hline
\end{tabular}


Supplemental data 2: Distribution of RET germline pathogenic non SNP variants in European families. The table is modified from the 2013 manuscript by Machens et $a l$. (19)

\begin{tabular}{|c|c|c|c|c|c|}
\hline Variants non SNPs RET classify in ATA & \begin{tabular}{|l|} 
Italy \\
(n=244 \\
) (18)
\end{tabular} & $\begin{array}{l}\text { German } \\
(n=205) \\
(19)\end{array}$ & $\begin{array}{l}\text { Spain } \\
(n=25) \\
(21)\end{array}$ & \begin{tabular}{|l} 
Greece \\
$(n=58)$ \\
$(20)$
\end{tabular} & $\begin{array}{l}\text { France } \\
(n=48 \\
0)\end{array}$ \\
\hline 532 duplication & & & & & $1(0.2)$ \\
\hline C515S & $1(0.4)$ & & & & $3(0.6)$ \\
\hline G533C & & & & $\begin{array}{l}21 \\
(36.2)\end{array}$ & $3(0.6)$ \\
\hline K603E & & & & & $1(0.2)$ \\
\hline $\mathrm{C} 609 \mathrm{~F}=\mathrm{R}=\mathrm{G}=\mathrm{S}=\mathrm{Y}$ & $6(2.5)$ & $1(0.5)$ & $1(3.9)$ & & $5(1.0)$ \\
\hline $\mathrm{C} 611 \mathrm{R}=\mathrm{G}=\mathrm{F}=\mathrm{S}=\mathrm{W}=\mathrm{Y}$ & $1(0.4)$ & $6(3)$ & & & $\begin{array}{l}12 \\
(2.5)\end{array}$ \\
\hline $\mathrm{C} 618 \mathrm{R}=\mathrm{G}=\mathrm{F}=\mathrm{S}=\mathrm{Y}$ & $\begin{array}{l}15 \\
(6.1)\end{array}$ & $11(5)$ & $\begin{array}{l}1 \\
(3.85)\end{array}$ & $4(6.9)$ & $29(6)$ \\
\hline $\mathrm{C} 620 \mathrm{R}=\mathrm{G}=\mathrm{F}=\mathrm{S}=\mathrm{W}=\mathrm{Y}$ & $9(3.7)$ & $14(7)$ & $\begin{array}{l}1 \\
(3.85)\end{array}$ & $5(8.6)$ & $\begin{array}{l}31 \\
(6.4)\end{array}$ \\
\hline $\mathrm{C} 630 \mathrm{R}=\mathrm{F}=\mathrm{S}=\mathrm{Y}$ & $4(1.6)$ & $1(0.5)$ & & & $1(0.2)$ \\
\hline $\mathrm{C} 634 \mathrm{R}=\mathrm{G}=\mathrm{F}=\mathrm{S}=\mathrm{W}=\mathrm{Y}$ & $\begin{array}{l}85 \\
(34.8)\end{array}$ & $73(36)$ & $\begin{array}{l}17 \\
(65.4)\end{array}$ & $\begin{array}{l}19 \\
(32.8)\end{array}$ & $\begin{array}{l}144 \\
(29.9)\end{array}$ \\
\hline S649L & & & & & $2(0.4)$ \\
\hline K666E & & & & & $1(0.2)$ \\
\hline E768D & $9(3.7)$ & $2(1)$ & $1(3.9)$ & $1(1.7)$ & $\begin{array}{l}14 \\
(2.9)\end{array}$ \\
\hline L790F & $8(3.3)$ & $26(13)$ & & & $\begin{array}{l}43 \\
(8.9)\end{array}$ \\
\hline Y791F * & $2(0.8)$ & $14(7)$ & & & $7(1.5)$ \\
\hline V804L & $3(1.2)$ & $19(9)$ & & $3(5.2)$ & $\begin{array}{l}12 \\
(2.5)\end{array}$ \\
\hline
\end{tabular}




\begin{tabular}{|c|c|c|c|c|c|}
\hline V804M & $\begin{array}{l}49 \\
(20.2)\end{array}$ & & & & $\begin{array}{l}83 \\
(17.2)\end{array}$ \\
\hline A883F & & & & & $2(0.4)$ \\
\hline S891A & $\begin{array}{l}23 \\
(9.4)\end{array}$ & $6(3)$ & $\begin{array}{l}1 \\
(3.85)\end{array}$ & & $\begin{array}{l}20 \\
(4.1)\end{array}$ \\
\hline R912P & & & & & $1(0.2)$ \\
\hline M918T & $\begin{array}{l}17 \\
(7.0)\end{array}$ & $32(16)$ & $3(11.5)$ & $5(8.6)$ & $\begin{array}{l}30 \\
(6.0)\end{array}$ \\
\hline non-SNP RET variants, non classified in ATA & $\begin{array}{l}12 \\
(4.9)\end{array}$ & & & & $\begin{array}{l}36 \\
(7.5)\end{array}$ \\
\hline
\end{tabular}

* Erlic et al (6), Toledo et al (5), and ARUP MEN 2 data base classified Y791F as a rare nonpathogenic variant wherease ATA MTC guidelines in 2009 and 2015 considered this variant as pathogenic variant. 